\title{
Lycopene Synthesis and Related Gene Expression in Pummelo Pulp Increased in Shade-grown Fruit
}

\author{
Paemika Promkaew \\ School of Bioresources and Technology, King Mongkut's University of Technology Thonburi, \\ Bangkhuntien, Bangkok 10150, Thailand; and Graduate School of Horticulture, Chiba University, \\ Matsudo, 271-8510, Japan \\ Varit Srilaong, Chalermchai Wongs-Aree, and Nutthachai Pongprasert \\ School of Bioresources and Technology, King Mongkut's University of Technology Thonburi, \\ Bangkhuntien, Bangkok 10150, Thailand
}

Samak Kaewsuksaeng

Faculty of Technology and Community Development, Thaksin University, Phatthalung 93110, Thailand

\author{
Satoru Kondo \\ Graduate School of Horticulture, Chiba University, Matsudo 271-8510, Japan
}

\begin{abstract}
Additional INDEX words. abscisic acid, bagging, carotenoid, Citrus maxima, temperature
Aвstract. The effects of bagging-induced light reductions on lycopene synthesis and the expression of related genes, antioxidant activity, and sugar composition of 'Tubtim Siam' pummelo (Citrus maxima) were investigated. Glucose, ascorbic acid, and flavonoid concentrations and 2, 2-diphenyl-1-picryhydrazyl scavenging activity were decreased in fruit covered with bags while still on the tree $\left[0.01 \mu \mathrm{mol} \cdot \mathrm{m}^{-2} \cdot \mathrm{s}^{-1}\right.$ photosynthetic photon flux density $\left.(P P F D)\right]$ compared with the untreated control $\left(596.7 \mu \mathrm{mol} \cdot \mathrm{m}^{-2} \cdot \mathrm{s}^{-1} P P F D\right)$. The bagging treatment significantly decreased the temperatures on the surface in the bag. In addition, the bagging treatment decreased abscisic acid concentrations in the peel and pulp. However, the bagging treatment increased lycopene concentrations, upregulated phytoene synthase $(C s P S Y)$ and $\zeta$-carotene desaturase (CsZDS) gene expressions; downregulated chromoplast-specific lycopene cyclase $(C s \beta L C Y), \beta$-carotene hydroxylase $(C s \beta C H X)$, and $\varepsilon$-ring hydroxylase $(C s \mathcal{E} C H X)$; and decreased 9-cis-epoxycarotenoid dioxygenase ( $C s N C E D 1)$ gene expressions in the pulp. It is possible that maintaining a temperature of $\approx 25^{\circ} \mathrm{C}$ in fruit covered with bags may increase the lycopene concentration in the pulp with the upregulation of $C s P S Y$ and $C s Z D S$ and the downregulation of $C s \beta L C Y, C s \beta C H X, C s \mathcal{E} C H X$, and $C s N C E D 1$ gene expressions in the pulp.
\end{abstract}

'Tubtim Siam' pummelo (Citrus maxima) is a geographical indication (GI) product with a ruby red pulp and a sweet aroma (Kaewtubtim and Issarakraisila, 2016). 'Tubtim Siam' pummelo with redder pulp has a high added value. However, the degree of pulp coloration varies in each fruit and may be influenced by environmental conditions. The pummelo peel is generally yellow or green when mature, depending on environmental factors (Porras et al., 1996). Carotenoids, which are isoprenoid-derived pigments, accumulate in the peel and pulp of citrus fruit [Citrus sp. (Kato et al., 2004)]. Lycopene exhibits the highest physical quenching rate among carotenoids (Lindshield et al., 2007; Roldan-Gutierrez and de Castro, 2007). The higher expression levels of $P S Y$ and $Z D S$ genes and the lower expression levels of $\beta L C Y \mathrm{~s}$ are key factors triggering lycopene accumulation in sweet orange [C. sinensis (Xu et al., 2010)] (Fig. 1). In addition, lycopene is related to a lower expression level of the fruit-specific $\beta L C Y 2$ gene in red grapefruit [C. paradisi (Alquézar et al., 2013; Mendes et al., 2011)].

Lycopene accumulates in only a few species of citrus fruits, such as grapefruit (C. paradisi) and pummelo (C. grandis)

Received for publication 21 Aug. 2019. Accepted for publication 15 Oct. 2019. Published online 27 November 2019.

S. Kondo is the corresponding author. E-mail: s-kondo@faculty.chiba-u.jp.

This is an open access article distributed under the CC BY-NC-ND license (https://creativecommons.org/licenses/by-nc-nd/4.0/).
(Alquézar et al., 2013; Liu et al., 2007). Lycopene synthesis is initiated by the upregulation of phytoene synthase (PSY) followed by increments of phytoene desaturase (PDS), $\zeta$-carotene desaturase (ZDS), and $\beta$-carotene hydroxylase $(\beta-\mathrm{CHX})$ and the induction of chromoplast-specific lycopene cyclase ( $\beta \mathrm{LCY}$ ) and lycopene $\varepsilon$-cyclase (ELCY) (Cunningham, $2002)$. $\alpha$-Carotene is converted to lutein by sequential hydroxylation, which is catalyzed by $\varepsilon$-ring hydroxylase $(\mathcal{E} H \mathrm{HX})$ and $\beta$-ring hydroxylase ( $\beta C H X)$. $\beta$-Carotene is converted to zeaxanthin via $\beta$-cryptoxanthin by two-step hydroxylation, which is catalyzed by $\beta \mathrm{CHX}$. Furthermore, zeaxanthin is converted to violaxanthin via antheraxanthin by zeaxanthin epoxidase (Alquézar et al., 2013; Kato et al., 2004; Rodrigo et al., 2004). The catabolism of some carotenoids influences carotenoid accumulation, such as that of cis-violaxanthin. The 9-cisepoxycarotenoid dioxygenase, which catalyzes a limiting step in abscisic acid (ABA) biosynthesis, is involved in the regulation of carotenoid accumulation (Fig. 1). There are some reports on factors that affect peel color (Alquézar et al., 2013; Kato et al., 2004; Rodrigo et al., 2004). However, few studies have examined factors that affect carotenoid accumulation and related gene expression in pummelo pulp.

Light is one of the most crucial environmental factors in carotenoid accumulation in plant tissues (Pizarro and Stange, 2009). Light has been shown to induce carotenoid accumulation and carotenoid biosynthetic genes in tomato fruit [Solanum 


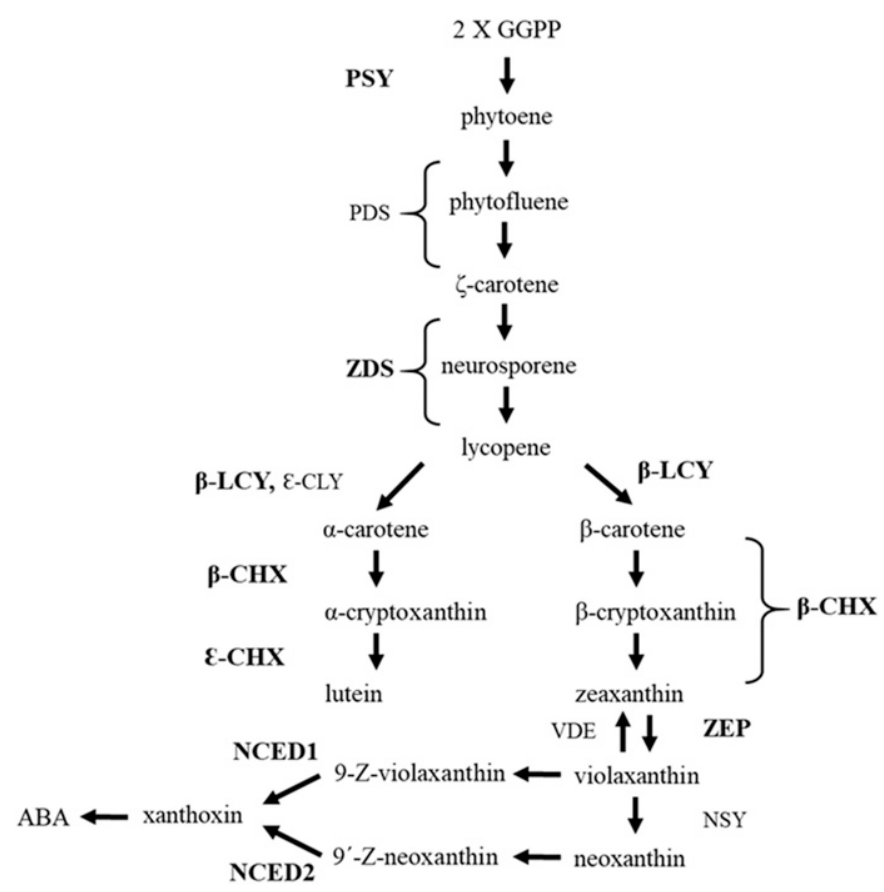

Fig. 1. The metabolic pathway of carotenoid in pulp of 'Tubtim Siam' pummelo fruit. Genes analyzed in this study are shown in boldface. GGPP = geranylgeranyl diphosphate; PSY = phytoene synthase; PDS = phytoene desaturase; ZDS $=\zeta$-carotene desaturase; $\mathcal{E}$-LCY $=$ lycopene $\mathcal{E}$-cyclase; $\beta$-LCY $=$ lycopene $\beta$-cyclase $; \beta$-CHX $=\beta$-carotene hydroxylase; $\mathcal{E}$ - $\mathrm{CHX}=$ $\mathcal{E}$-carotene hydroxylase; $\mathrm{ZEP}=$ zeaxanthin epoxidase; $\mathrm{VDE}=$ violaxanthin de-epoxidase; NSY = neoxanthin synthase; $\mathrm{NCED}=$ nine-cis-epoxycarotenoid dioxygenase; $\mathrm{ABA}=$ abscisic acid.

Table 1. Gene-specific primer sets used for quantitative real-time reverse transcription polymerase chain reaction analyses of $C s P S Y, C s Z D S, C s \beta-L C Y, C s \beta-C H X, C s \mathcal{E}-C H X$, CsZEP, and CsNCED in pulp of 'Tubtim Siam' pummelo fruit.

\begin{tabular}{|c|c|c|}
\hline Gene & Forward/reverse primer $\left(5^{\prime}-3^{\prime}\right)$ & Reference \\
\hline \multirow[t]{2}{*}{ CsPSY } & GGTCGTCCATTTGATATGCTTG & Fanciullino et al., 2008 \\
\hline & CCTAAGGTCCATCCTCATTCCT & \\
\hline \multirow[t]{2}{*}{$C s Z D S$} & CGATCCTTACATGCCCTTAC & \\
\hline & AGGTCCCTCACGGTACAAAG & \\
\hline \multirow[t]{2}{*}{$C s \beta L C Y$} & CCCATGTATGACCCATCAAAG & \\
\hline & TGGGAGATGGATCAATCGAG & \\
\hline \multirow[t]{2}{*}{$\mathrm{Cs} \beta C H X$} & GGTGCTGGACTTGGCATTAC & \\
\hline & AGCGACTCTCCGGAAATAAG & \\
\hline \multirow[t]{2}{*}{$C s \mathcal{E} C H X$} & CGGCACCAAGTATGCTAAAGG & \\
\hline & CAGCAGTTCCATTTAGAGGG & \\
\hline \multirow[t]{2}{*}{ CsZEP } & TTGGTTGATGGGATTTCTGG & \\
\hline & TCCCCAACCGCTTTAGCTAG & \\
\hline \multirow[t]{2}{*}{ CsNCEDI } & GGTGCCAACCCATTATTCGA & Kato et al., 2006 \\
\hline & GCCGTCACCGTCAAAGAAAT & \\
\hline \multirow[t]{2}{*}{ CsNCED2 } & CATTCAAGGCGTCTACGTCAGA & \\
\hline & CGGCGACCGGTTCGT & \\
\hline \multirow[t]{2}{*}{ CsActin } & ATCTGCTGGAAGGTGCTGAG & Wu et al., 2014 \\
\hline & CCAAGCAGCATGAAGATCAA & \\
\hline \multirow[t]{2}{*}{$C s G A P D H$} & GTGTTTCTATGTAGAGGGTCTGAGTTT & \\
\hline & TCTAAGCACAACCCTGCATGAG & \\
\hline \multirow[t]{2}{*}{ CsUBL5 } & CTCGAGCCGACAAGATTCG & \\
\hline & CCATGCCGTCGTGAATCTC & \\
\hline
\end{tabular}

$\mathrm{PSY}=$ phytoene synthase ZDS $=\zeta$-carotene desaturase $; \beta$-LCY $=$ lycopene $\beta$-cyclase $\beta$-CHX $=$ $\beta$-carotene hydroxylase; $\mathcal{E}$-CHX $=\mathcal{E}$-carotene hydroxylase; $\mathrm{ZEP}=$ zeaxanthin epoxidase $\mathrm{NCED}=$ nine-cis-epoxycarotenoid dioxygenase. lycopersicum (Azari et al., 2010; Schofield and Paliyath, 2005)]. In contrast, darkness induced carotenoid accumulation in carrot roots [Daucus carota (Fuentes et al., 2012; Rodríguez-Concepcion and Stange, 2013)]. The accumulation of carotenoids in darkness correlated with upregulated activity of PSY, the first committed enzyme of carotenogenesis) and with the induction of PSY gene expression in cotyledons in arabidopsis seedlings [Arabidopsis thaliana (Villalón et al., 2009)]. These reports suggest that the effects of environmental conditions on carotenoid synthesis may vary among plant species. This study investigated the effects of bagging-induced reductions in light conditions on lycopene production and related gene expression, antioxidant capacity, and sugar composition in pummelo.

\section{Materials and Methods}

Plant samples and treatments. The experiments were carried out in a commercial orchard in Thailand (lat. $8.34^{\circ} \mathrm{N}$, long. $100.09^{\circ} \mathrm{E}$ ) with an average $P P F D$ of $1112 \mu \mathrm{mol} \cdot \mathrm{m}^{-2} \cdot \mathrm{s}^{-1}$ and average rainfall of $2665 \mathrm{~mm} \cdot$ year $^{-1}$ (data from 1943 to 2018). Eight-year-old trees of 'Tubtim Siam' pummelo were selected randomly and used for the experiment in 2017 and 2018. Fruit from the outer part of the canopy from each of three trees were tagged at fruit set, after which half of the tagged fruit were covered with bagging paper $(0.01$ $\mu \mathrm{mol} \cdot \mathrm{m}^{-2} \cdot \mathrm{s}^{-1}$ of $P P F D$ ) while in an immature green stage [June, 3 months after fruit set (MAFS)]. Three replicates of five fruit each (15 fruit per treatment) were sampled in June (3 MAFS) and in the mature green stage (July, 4 MAFS), breaker stage [August, 5 MAFS), after breaker stage (September, 6 MAFS), and at full color (October, 7 MAFS). Peels and pulp were immediately frozen in liquid nitrogen, ground to a fine powder, and stored at $-80{ }^{\circ} \mathrm{C}$ until analysis.

A N A L Y S E S O F S U G A R, CAROTENOID, FLAVONOID, ASCORBIC ACID, CHLOROPHYLL, ANTIOXIDANT ACTIVITY, AND ABA. The sugar concentrations were analyzed as reported by Kondo et al. (2014). A 1 -g freeze-dried pulp sample (three replications) in $10 \mathrm{~mL} 80 \%(\mathrm{v} / \mathrm{v})$ ethanol was boiled for $15 \mathrm{~min}$, cooled, and then homogenized. The homogenate was filtered and evaporated. The residue was redissolved in $3 \mathrm{~mL}$ distilled water and analyzed using high-performance liquid chromatography [HPLC (model L-6200; Hitachi, Tokyo, Japan)] with a polymer-based column [4.6 mm i.d. $\times 25 \mathrm{~cm}$ (Shodex ODP2 HP-4E; Showa Denko, Tokyo, Japan)]. The column temperature was set at $30{ }^{\circ} \mathrm{C}$ and the mobile phase flow rate was $1 \mathrm{~mL} \cdot \mathrm{min}^{-1}(75 \% \mathrm{v} / \mathrm{v}$ acetonitrile). A refractive index detector was used to identify sugar components.

Carotenoid concentrations were measured according to Fish et al. (2002). Concentrations from the $0.5-\mathrm{g}$ freeze-dried samples (three replications) were extracted with hexane, ethanol, and acetone containing $0.05 \%$ 
butylated hydroxytoluene and determined at different absorbances at $445 \mathrm{~nm}$ for total carotenoids, $450 \mathrm{~nm}$ for $\beta$-carotene, and $503 \mathrm{~nm}$ for lycopene using a spectrophotometer (ultraviolet-1800; Shimadzu, Kyoto, Japan). Flavonoid concentrations were measured according to Zhishen et al. (1999). Concentrations from the 0.5-g freeze-dried samples (three replications) were extracted with 100 $\mathrm{mL}$ ethanol for $1 \mathrm{~h}$. After the addition of $\mathrm{NaNO}_{2}, \mathrm{AlCl}_{3}$, and $\mathrm{NaOH}$, absorbance was measured at $510 \mathrm{~nm}$ using the spectrophotometer. Ascorbic acid concentrations ( $0.5 \mathrm{~g}$ of pulp, three replications) were measured according to the 2,4-dinitrophenylhydrazine (DNPH) method (Kapur et al., 2012). Absorbance was measured at $540 \mathrm{~nm}$. Chlorophyll concentrations were measured according to the method of Inskeep and Bloom (1985). Chlorophyll (0.5 g peel, three replications) was extracted with $20 \mathrm{~mL}$ of N,N-dimethylformamide. The concentrations were measured by absorbance of 647 and $664 \mathrm{~nm}$.

Antioxidant activity was measured by the 2,2-diphenyl-1picryhydrazyl (DPPH) scavenging activity method according to Kondo et al. (2004). Pulp (0.5 g, three replications) was homogenized in $80 \%$ ethanol. After the homogenate was centrifuged for $10 \mathrm{~min}$ at $12,000 \mathrm{~g}_{\mathrm{n}}$ at $4{ }^{\circ} \mathrm{C}, 150 \mu \mathrm{L}$ of the

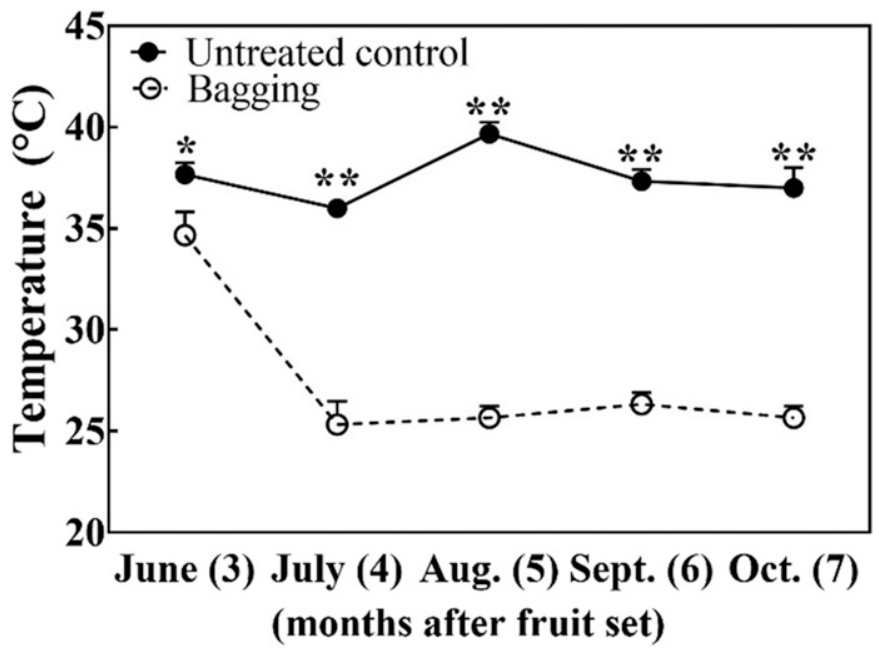

Fig. 2. The temperature inside the bag (number of months after fruit set is shown in parentheses) during fruit development from 3 months after fruit set (June) to harvest at 7 months after fruit set (October) in 'Tubtim Siam' pummelo fruit. Each value represents the mean $\pm \mathrm{SE} . *{ }^{*} *$ Significant difference by $t$ test at $P \leq 0.05$ or 0.01 on each date, respectively.

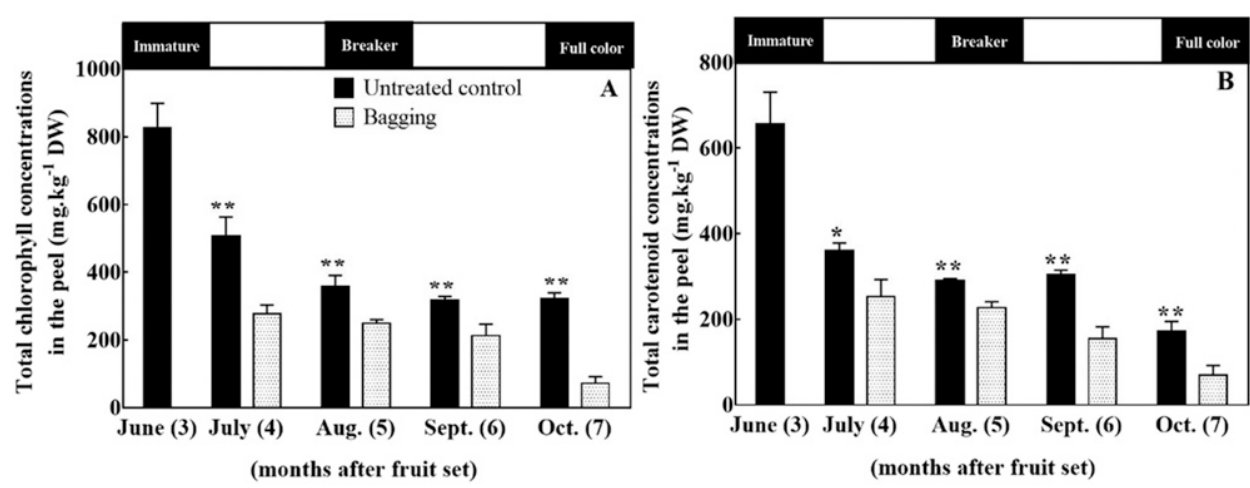

Fig. 3. Effects of bagging on chlorophyll (A) and carotenoid concentration (B) in peel of 'Tubtim Siam' pummelo fruit (number of months after fruit set is shown in parentheses). Each value represents the mean \pm SE. *, ** Significant difference by $t$ test at $P \leq 0.05$ or 0.01 on each date, respectively. extract was added to $2.85 \mathrm{~mL}$ of a $0.2 \mathrm{mmol} \mathrm{DPPH}-\mathrm{methanolic}$ solution. Absorbance was measured at $515 \mathrm{~nm}$.

The ABA concentrations were analyzed according to Kondo et al. (2014). The samples ( $1 \mathrm{~g}$, three replications) were homogenized in a $20-\mathrm{mL}$ solution of $80 \% \mathrm{v} / \mathrm{v}$ methanol with $0.1 \% \mathrm{~L}(+)$ ascorbic acid (Kanto Chemical Co., Tokyo, Japan) and 0.1\% butylated hydroxytoluene [BHT (2, [6]-di-tert-butyl-p-cresol; Sigma-Aldrich, St. Louis, MO)] using 0.2 $\mu \mathrm{g} \mathrm{ABA-} d_{6}$ as an internal standard. The homogenate was filtered, and the residue was washed with $20 \mathrm{~mL}$ of the initial methanol solution and then concentrated to an aqueous solution in vacuo. The $\mathrm{pH}$ was subsequently adjusted to 2.5 with $0.1 \mathrm{M}$ phosphoric acid and extracted three times with $20 \mathrm{~mL} 100 \% \mathrm{v} / \mathrm{v}$ ethyl acetate to concentrate it to dryness and then dissolved in $1 \mathrm{~mL}$ of $25 \%$ acetonitrile containing $20 \mathrm{~mm}$ acetic acid. The solution was filtered and then subjected to preparative HPLC for $30 \mathrm{~min}$; flow rate, 1.5 $\mathrm{mL} \cdot \mathrm{min}^{-1}$; detection at $254 \mathrm{~nm}$ ) equipped with a difunctional octadecylsilyl column $(250 \times 4.6 \mathrm{~mm}$ i.d.; Mightysil RP-18, Kanto Chemical Co.) eluted with a gradient of $25 \%$ to $50 \%$ acetonitrile containing $20 \mathrm{~mm}$ acetic acid, and held at 50\% acetonitrile for 5 min. The fractions containing ABA were collected, dried in vacuo, and methylated using ethereal diazomethane for $10 \mathrm{~min}$. The methyl ester of ABA was analyzed by gas chromatography-mass spectrometry selected ion monitoring (model QP5000, Shimadzu). The column temperature was a step gradient of $60^{\circ} \mathrm{C}$ for $2 \mathrm{~min}$, followed by 60 to $270{ }^{\circ} \mathrm{C}$ at $10^{\circ} \mathrm{C} \cdot \mathrm{min}^{-1}$ and $270{ }^{\circ} \mathrm{C}$ for $35 \mathrm{~min}$. Ions were measured as $\mathrm{ABA}-d_{0}$ methylester/ABA- $d_{6}$ methyl ester at $m / z 190,260,194$, and 264. The ABA concentration was calculated from the ratio of peak areas for $m / z 190\left(d_{0}\right) / 194\left(d_{6}\right)$.

Total RNA Extraction. Total RNA was isolated from the pulp at each sampling date. Each 100-mg pulp sample was ground in liquid nitrogen, thoroughly mixed with $1 \mathrm{~mL}$ trizol, and transferred to a centrifuge tube. The mixture was centrifuged for $10 \mathrm{~min}$ at $12,000 \mathrm{~g}_{\mathrm{n}}$ at $4{ }^{\circ} \mathrm{C}$. The upper aqueous phase was transferred into a new centrifuge tube, after which $240 \mu \mathrm{L}$ chloroform was added and thoroughly mixed on ice for $5 \mathrm{~min}$, followed by centrifuging for $15 \mathrm{~min}$ at $12,000 \mathrm{~g}_{\mathrm{n}}$ at $4{ }^{\circ} \mathrm{C}$. The upper aqueous phase was further transferred into another centrifuge tube, and $500 \mu \mathrm{L}$ of isopropanol and $0.3 \mathrm{~mL}$ of a high-salt precipitation solution ( $2 \mathrm{M}$ of sodium citrate and sodium chloride) was added to each sample and left to precipitate for $10 \mathrm{~min}$ at room temperature. The mixture was then centrifuged for $10 \mathrm{~min}$ at $12,000 g_{\mathrm{n}}$ at $4{ }^{\circ} \mathrm{C}$. The upper aqueous phase was withdrawn, and the remaining RNA pellet was dried. The RNA pellet was then washed using $1 \mathrm{~mL} \mathrm{75 \%}$ ethanol, and total RNA was precipitated by centrifuging for $5 \mathrm{~min}$ at $12,000 g_{\mathrm{n}}$ at $4{ }^{\circ} \mathrm{C}$ (this was performed twice). Total RNA was treated with Recombinant DNase I [RNase-free (Takara Bio, Otsu, Japan)]. The RNA pellets were completely air dried for $5 \mathrm{~min}$, after which the RNA was dissolved in $50 \mu \mathrm{L}$ of RNase-free water and then stored at $-80^{\circ} \mathrm{C}$.

Quantitative REAL-TIME POLYMERASE CHAIN REACTION ANALYSIS. cDNA was synthesized from the extracted RNA using the iScript Reverse Transcription Supermix for RT-qPCR (Bio-Rad Laboratories, Hercules, CA). Quantitative 
real-time polymerase chain reaction (PCR) was performed using a SYBR Green FAST ABI Prism qPCR Kit (Kapa Biosystems, Wilmington, MA) according to the instruction manual. Gene-specific primers of $C s P S Y, C s Z D S, C s \beta L C Y$, Cs $\beta C H X, C s \mathcal{E} C H X$, CsZEP (Fanciullino et al., 2008),

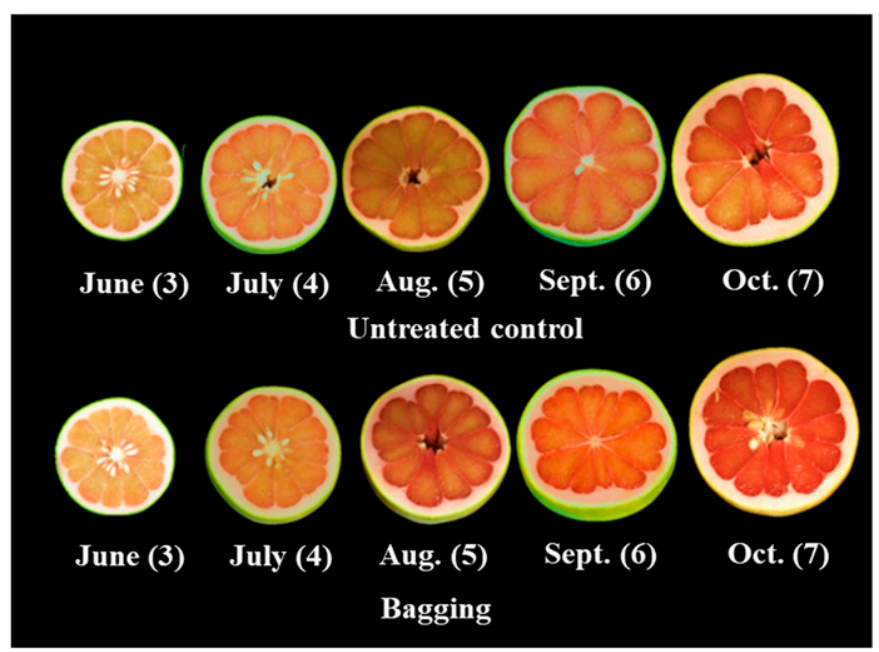

Fig. 4. The pulp coloration in 'Tubtim Siam' pummelo fruit (number of months after fruit set is shown in parentheses).
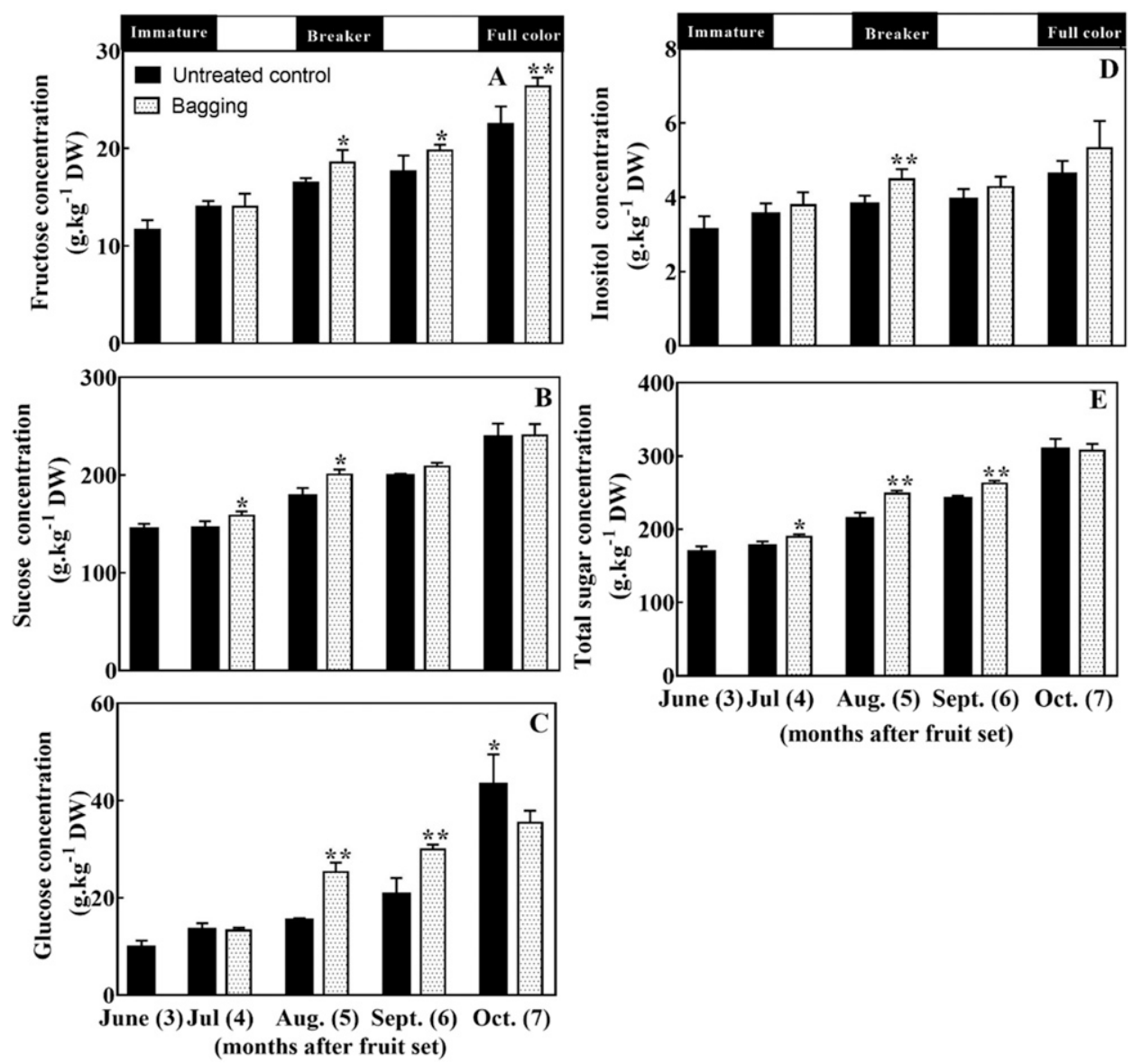

Fig. 5. Effects of bagging on fructose (A), sucrose (B), glucose (C), inositol (D), and total sugar (E) concentrations in pulp of 'Tubtim Siam' pummelo fruit (number of months after fruit set is shown in parentheses). Each value represents the mean $\pm \mathrm{SE}$. *, **Significant difference by $t$ test at $P \leq 0.05$ or 0.01 on each date, respectively.
CSNCED1, and CSNCED2 (Kato et al., 2004) for each gene were used for PCR (Table 1). The cycling protocol consisted of $95^{\circ} \mathrm{C}$ for $20 \mathrm{~s}$, followed by 40 cycles of $95^{\circ} \mathrm{C}$ for $3 \mathrm{~s}, 60^{\circ} \mathrm{C}$ for $30 \mathrm{~s}$, and $95{ }^{\circ} \mathrm{C}$ for $15 \mathrm{~s}$, followed by further 40 cycles to construct a melting curve. The specificity of the reactions was verified by melting curve analysis at 60 to $95^{\circ} \mathrm{C}$ after 40 cycles. Tree biological replicates were used during analysis. The transcript levels of target genes were estimated by the $2^{-\Delta \Delta \mathrm{CT}} 2$ algorithm, and these levels normalized against the transcript level of geometric averages of CsActin, CsGAPDH, and CsUBL5 in each sample (Wu et al., 2014).

Statistical AnAlysis. The data were presented as mean values \pm SE and evaluated by the $t$ test at the $1 \%$ or $5 \%$ level (SPSS 18; IBM Corp., Armonk, NY).

\section{Results}

EFFECT OF BAgGing ON CHANGE IN TEMPERATURE. In general, the temperature (average from 0600 to $1800 \mathrm{HR}$ ) on the fruit surface in the bag was significantly lower than that of the untreated control. The temperature on the fruit surface in the bag was $\approx 25^{\circ} \mathrm{C}$, and the temperature on the fruit surface of the untreated control was 35 to $40{ }^{\circ} \mathrm{C}$ (Fig. 2).

EFFECTS OF BAGGING TREATMENT ON CHLOROPHYLL, CAROTENOID, SUGAR, FLAVONOID, ASCORBIC ACID, ANTIOXIDANT ACTIVITY, AND CAROTENOID BIOSYNTHESIS GENE EXPRESSION. The concentrations of chlorophyll and carotenoid in the peel gradually declined after 3 MAFS (Fig. 3A and B). The fruit covered with bags showed significantly lower chlorophyll and carotenoid concentrations after 3 MAFS compared with the untreated control.

The pulp turned yellow after 3 MAFS in the fruit covered with bags and the untreated control fruit. The pulp of the fruit covered with bags was redder than that of the untreated control (Fig. 4).

The fructose concentrations after the breaker stage (5 MAFS) were significantly higher in the fruit covered with bags than in the untreated control. The total sugars, sucrose, and inositol concentrations at the breaker stage were also significantly higher in the fruit covered with bags than in the untreated control, although total sugar did not differ significantly between the two treatments (Fig. 5A, B, D, and E).

The lycopene and $\beta$-carotene concentrations in the fruit covered with bags were significantly lower than those in the untreated control fruit in July (4 MAFS). However, the lycopene, $\beta$-carotene, and total carotenoid concentrations in the fruit covered with bags were significantly increased after the breaker stage compared with the untreated 

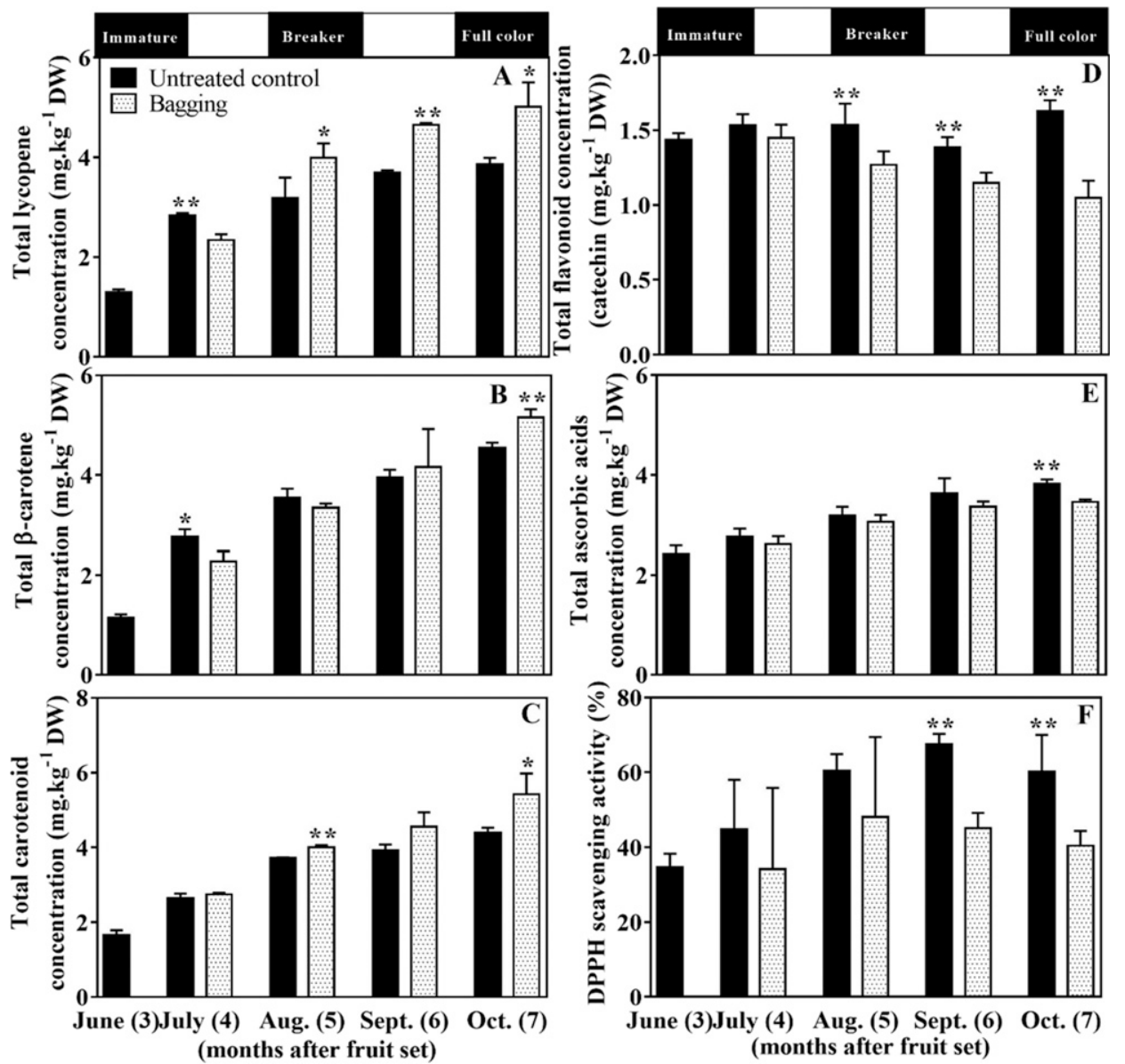

Fig. 6. Effects of bagging on the concentrations of lycopene $(\mathbf{A}), \beta$-carotene $(\mathbf{B})$, total carotenoid (C), flavonoid (D), ascorbic acid (E), and 2,2-diphenyl-1-picrylhydrazyl (DPPH) scavenging activity (F) in pulp of 'Tubtim Siam' pummelo fruit (number of months after fruit set is shown in parentheses). Each value represents the mean \pm SE. *, **Significant difference by $t$ test at $P \leq 0.05$ or 0.01 on each date, respectively.

control (Fig. 6A-C). The concentrations of flavonoid (Fig. 6D) and ascorbic acid (Fig. 6E) and the DPPH scavenging activity (Fig. 6F) were lower in the fruit covered with bags than in the untreated control fruit at 7 MAFS.

The CsPSY and CsZDS gene expression levels were significantly higher in the fruit covered with bags than in the untreated control fruit after the breaker stage. In contrast, the expression levels of $C s \beta L C Y, C s \beta C H X$, and $C s \mathcal{E} C H X$ were lower in the fruit covered with bags than in the untreated control fruit after the immature stage. However, the expression of $C s \beta L C Y$ was significantly higher in the fruit covered with bags than in the untreated control fruit at 7 MAFS. In the fruit covered with bags, the expression of the CsZEP gene was significantly higher in the 4 and 5 MAFS but lower at 7 MAFS. CSNCED1 gene expression levels were significantly lower in the fruit covered with bags than in the untreated control fruit. In both the peel and pulp, the ABA concentrations in the fruit covered with bags were significantly lower than in the untreated control fruit after the breaker stage (Fig. 7).

\section{Discussion}

It has been shown that bagging ( $0 \%$ light transmittance) decreased the flavonoid, carotenoid, and vitamin $\mathrm{C}$ content; antioxidant capacity; and sugar concentrations in the pulp of loquat fruit [Eriobotrya japonica (Huang et al., 2007)]. Our study also showed that the pummelo fruit covered with bags had lower glucose, ascorbic acid, flavonoid, and DPPH scavenging activity in the pulp and reduced chlorophyll in the peel compared with the untreated control fruit. It has been shown that the greenness of 'Tabtim Siam' pummelo peel was not significantly different from 5 to 8 MAFS when at the maturation stage (Kongsri and Nartvaranant, 2019). Our study also showed that both chlorophyll and carotenoid concentrations decreased toward harvest. In general, high temperature exhausts carbohydrates such as sugar in citrus (Holland et al., 2005). Noro et al. (1989) reported that the concentrations of fructose were higher in the fruit covered with bags than in the untreated control apples (Malus domestica). In addition, some studies have indicated that low temperatures during fruit maturation were associated with increased sugar levels in apples (Yamada et al., 1988) and tomatoes (Walker and Ho, 1977). Our study also revealed that the pulp of fruit covered by bags had higher fructose, sucrose, inositol, and total sugar concentrations at the breaker stage than the untreated control. Temperature $\approx 25{ }^{\circ} \mathrm{C}$ may therefore have contributed to the high sugar concentrations in the pummelo fruit covered with bags in our study.

Lycopene and $\beta$-carotene are the major pigments in red grapefruit cultivars (Lindshield et al., 2007; Roldan-Gutierrez and de Castro, 2007), and their concentrations have a significant relationship with color (Lee, 2001). Red orange (C. sinensis) accumulated lycopene with higher expression levels of CsPSY and $C s Z D S$ genes and with lower $C s \beta L C Y$ expression levels (Xu et al., 2006). Furthermore, lycopene seems to be related to lower expression levels of $\beta L C Y 2$ gene in grapefruit (Alquézar et al., 2013). In general, light increased carotenoid levels in chromoplasts in tomato fruit (Liu et al., 2015). However, shade promoted chromoplast differentiation and carotenoid accumulation in grapefruit (Lado et al., 2015). In addition, dark conditions induced gene expression related to carotenoid synthesis by a putative repressor of photo morphogenesis that is encoded by the Y locus associated with carotenogenesis in carrot root (Iorizzo et al., 2016). Villalón et al. (2009) suggested that carotenoid biosynthesis was induced in dark conditions with the upregulation of phytoene synthase and the induction of CSPSY gene expression in cotyledons of arabidopsis. These reports support that the fruit covered with bags in our study showed high concentrations of lycopene and $\beta$-carotene concentration compared with the untreated control fruit with the upregulation of $C S P S Y$ and $C s Z D S$ and the downregulation of 


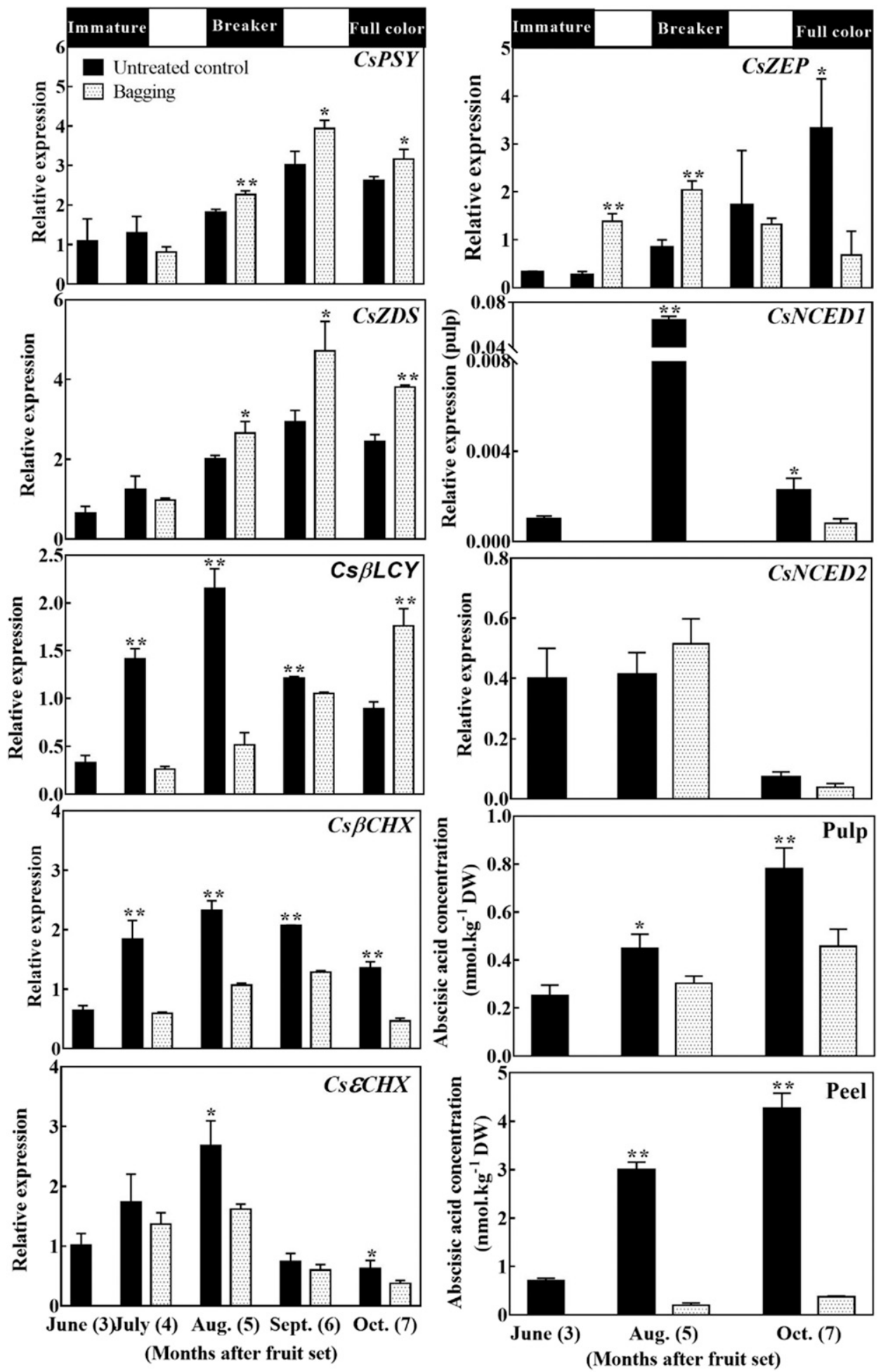

Fig. 7. Effects of bagging on the expression of carotenoid biosynthesis genes in pulp and abscisic acid concentrations in pulp and peel of 'Tubtim Siam' pummelo fruit (number of months after fruit sets is shown in parentheses). Each value represents the mean $\pm \mathrm{SE}$. *, **Significant difference by $t$ test at $P \leq 0.05$ or 0.01 on each date, respectively. PSY = phytoene synthase; $Z$ DS $=\zeta$-carotene desaturase; $\beta$-LCY $=$ lycopene $\beta$-cyclase; $\beta$-CHX $=\beta$-carotene hydroxylase; $\mathcal{E}$-CHX $=\mathcal{E}$-carotene hydroxylase $; \mathrm{ZEP}=$ zeaxanthin epoxidase; $\mathrm{NSY}=$ neoxanthin synthase; NCED = nine-cis-epoxycarotenoid dioxygenase.

$C s \beta L C Y, C s \beta C H X$, and $C s \mathcal{E} C H X$ gene expression. In addition, our results showed that the increase of lycopene was associated with the decrease of ABA concentration and CsNCEDI gene expression in the peel and pulp of the fruit covered with bags. In general, the increase of carotenoid is associated with the increase of ABA concentration in orange or white grapefruit (Alquézar et al., 2013). In addition, Lado et al. (2015) noted that dark conditions tended to decrease carotenoid concentrations in red grapefruit, resulting in a decreased endogenous ABA concentration. In our study, ABA and lycopene concentrations showed the opposite relationship. The results may show that another factor influenced lycopene concentrations in the fruit covered with bags. Some previous reports have suggested that the ABA concentrations decreased at low temperature and rose at high temperature in mangosteen fruit [Garcinia mangostana (Kondo and Jitratham, 2004)]. Hamauzu et al. (1995) also reported that tomato fruit changed from green to red during storage at $20{ }^{\circ} \mathrm{C}$ and changed to yellow at $30{ }^{\circ} \mathrm{C}$. Our study suggests that a temperature of $\approx 25{ }^{\circ} \mathrm{C}$ promoted lycopene synthesis but that temperatures $\approx 35$ to $40{ }^{\circ} \mathrm{C}$ inhibited synthesis in pummelo pulp.

\section{Literature Cited}

Alquézar, B., M.J. Rodrigo, J. Lado, and L. Zacarías. 2013. A comparative physiological and transcriptional study of carotenoid biosynthesis in white and red grapefruit (Citrus paradisi Macf.). Tree Genet. Genomes 9:1257-1269.

Azari, R., Y. Tadmor, A. Meir, M. Reuveni, D. Evenor, S. Nahon, H. Shlomo, L. Chen, and I. Levin. 2010. Light signalling genes and their manipulation towards modulation of phytonutrient content in tomato fruits. Biotechnol. Adv. 28:108-118.

Cunningham, F.X. 2002. Regulation of carotenoid synthesis and accumulation in plants. Pure Appl. Chem. 74:409-417.

Fanciullino, A.L., M. Cerćos, M.C. Dhique, Y. Froelicher, M. Talón, P. Ollitrault, and R. Morillon. 2008. Changes in carotenoid content and biosynthetic gene expression in juice sacs of four orange varieties (Citrus sinensis) differing in flesh fruit color. J. Agr. Food Chem. 56:3628-3638.

Fish, W.W., V.P. Perkins, and J.K. Collins. 2002. A quantitative assay for lycopene that utilizes reduced volumes of organic solvents. J. Food Compos. Anal. 15:309-317.

Fuentes, P., L. Pizarro, J.C. Moreno, M. Handford, C.M. Rodriguez, and C. Stange. 2012. Light-dependent changes in plastid differentiation influence carotenoid gene expression and accumulation in carrot roots. Plant Mol. Biol. 79:47-59. 
Hamauzu, Y., Y. Miyamoto, and K. Chachin. 1995. Effect of high temperatures on the change of carotenoid contents in tomato fruit after harvest. J. Jpn. Soc. Hortic. Sci. 63:675-684.

Holland, N.A., H.C. Menezes, and M.A.T. Lafuente. 2005. Carbohydrate metabolism as related to high-temperature conditioning and peel disorders occurring during storage of citrus fruit. J. Agr. Food Chem. 53:8790-8796.

Huang, C.H., M.L. Chai, Z.M. Pan, B. Yu, Z.M. Jiang, J.L. Hu, and Y.W. Teng. 2007. Effects of bagging on fruit skin features and quality of Cuiguan pear cultivar. Guoshu Xuebao 24:747-751.

Inskeep, W.P. and P.R. Bloom. 1985. Extinction coefficients of chlorophyll a and $\mathrm{b}$ in $\mathrm{N}, \mathrm{N}$ dimethylformamide and $80 \%$ acetone. Plant Physiol. 77:483-485.

Iorizzo, M., S. Ellison, and D. Senalik. 2016. A high-quality carrot genome assembly provides new insights into carotenoid accumulation and asterid genome evolution. Nat. Genet. 48:657-666.

Kaewtubtim, M. and M. Issarakraisila. 2016. Effects of nitrogen and zinc on fruit quality of pummelo cv. Tubtim Sayam. KKU Sci. J. 44:518-529.

Kapur, A., A. Hasković, A. Čopra-Janićijević, L. Klepo, A. Topčagić, I. Tahirović, and E. Sofić. 2012. Spectrophotometric analysis of total ascorbic acid content in various fruits and vegetables Bul. Chemists Technologists Bosnia Herzegovina 38:39-42.

Kato, M., Y. Ikoma, H. Matsumoto, M. Sugiura, H. Hyodo, and M. Yano. 2004. Accumulation of carotenoids and expression of carotenoid biosynthetic genes during maturation in citrus fruit. Plant Physiol. 134:824-837.

Kato, M., H. Matsumoto, Y. Ikoma, H. Okuda, and M. Yano. 2006. The role of carotenoid cleavage dioxygenases in the regulation of carotenoid profiles during maturation in citrus fruit. J. Expt. Bot. 57:2153-2164.

Kondo, S. and A. Jitratham. 2004. Relationships between jasmonates and chilling injury in mangosteens are affected by spermine. HortScience 39:1346-1348

Kondo, S., H. Tomiyama, A. Rodyoung, K. Okawa, H. Ohara, S. Sugaya, N. Terahara, and N. Hirai. 2014. Abscisic acid metabolism and anthocyanin synthesis in grape skin are affected by light emitting diode (LED) irradiation at night. J. Plant Physiol. 171:823-829.

Kondo, S., H. Yoshikawa, and R. Katayama. 2004. Antioxidant activity in astringent and non-astringent persimmons. J. Hortic. Sci. Biotechnol. 79:390-394.

Kongsri, S. and P. Nartvaranant. 2019. Fruit morphological characteristics and fruit quality of pomelo cv. 'Tabtim Siam' grown in Nakhon Pathon and Nakhon Si Thammarat Provinces. J. Thai Interdisciplinary Res. 14:5-11.

Lado, J., P. Cronje, B. Alque'zar, A. Page, M. Manzi, A. Go'mezCadenas, A.D. Stead, L. Zacarías, and M.J. Rodrigo. 2015. Fruit shading enhances peel color, carotenes accumulation and chromoplast differentiation in red grapefruit. Physiol. Plant. 154:469-484.

Lee, H.S. 2001. Characterization of carotenoids in juice of red navel orange (Cara Cara). J. Agr. Food Chem. 49:2563-2568.

Lindshield, B.L., K. Canene-Adams, and J.W. Erdman. 2007. Lycopenoids: Are lycopene metabolites bioactive. Arch. Biochem. Biophys. 458:136-140.

Liu, Q., J. Xu, Y.Z. Liu, X.L. Zhao, X.X. Deng, L.L. Guo, and J.Q. Gu. 2007. A novel bud mutation that confers abnormal patterns of lycopene accumulation in sweet orange fruit (Citrus sinensis Osbeck). J. Expt. Bot. 58:4161-4171.

Liu, L., Z. Shao, M. Zhang, and Q. Wang. 2015. Regulation of carotenoid metabolism in tomato. Mol. Plant 8:28-39.

Mendes, A.F.S., C. Chen, F.G. Gmitter, G.A. Moore, and M.G.C. Costa. 2011. Expression and phylogenetic analysis of two new lycopene $\beta$-cyclases from citrus paradisi. Physiol. Plant. 141:110.

Noro, S., N. Kudo, and T. Kitsuwa. 1989. Differences in sugar and organic acid contents between bagged and un-bagged fruits of the yellow apple cultivars, and the effect on development of anthocyanin. J. Jpn. Soc. Hortic. Sci. 58:17-24.

Pizarro, L. and C. Stange. 2009. Light-dependent regulation of carotenoid biosynthesis in plants. Cienc. Investig. Agrar. 36:143162.

Porras, I., A. García, C. Egea, A. Conesa, and M.F. García. 1996. Internal and external colour changes in different grapefruit varieties. Proc. Intl. Soc. 2:1113-1116.

Rodorigo, M.J., J.F. Marcos, and L. Zacaris. 2004. Biochemical and molecular analysis of carotenoid biosynthesis in flavedo of orange (Citrus sinensis L.) during fruit development and maturation. J. Agr. food Chem. 52:6724-6730.

Rodríguez-Concepcion, M. and C. Stange. 2013. Biosynthesis of carotenoids in carrot: An underground story comes to light. Arch. Biochem. Biophys. 1:1-7.

Roldan-Gutierrez, J.M. and M.D.L. de Castro. 2007. Lycopene: The need for better methods for characterization and determination. Trends Analyt. Chem. 26:163-170.

Schofield, A. and G. Paliyath. 2005. Modulation of carotenoid biosynthesis during tomato fruit ripening through phytochrome regulation of phytoene synthase activity. Plant Physiol. Biochem. 43:1052-1060.

Villalón, A.R., E. Gas, and M.R. Concepción. 2009. Phytoene synthase activity controls the biosynthesis of carotenoids and the supply of their metabolic precursors in dark grown arabidopsis seedlings. Plant J. 60:424-435.

Walker, A.J. and L.C. Ho. 1977. Carbon translocation in the tomato: Effects of fruit temperature on carbon metabolism and the rate of translocation. Ann. Bot. 41:825-832.

Wu, J.X., S.Y. Su, L.L. Fu, Y.J. Zhang, L.J. Chai, and H.L. Yi. 2014. Selection of reliable reference genes for gene expression studies using quantitative real-time PCR in navel orange fruit development and pummelo floral organs. Scientia Hort. 176:180-188.

Xu, C.J., P.D. Fraser, W.J. Wang, and P.M. Bramley. 2006. Differences in the carotenoid content of ordinary citrus and lycopeneaccumulating mutants. J. Agr. Food Chem. 54:5474-5481.

Xu, Q., Y. Liu, A. Zhu, X. Wu, J. Ye, K. Yu, W. Guo, and X. Deng. 2010. Discovery and comparative profiling of micro RNAs in a sweet orange red-flesh mutant and its wild type. BMC Genomics 11:246.

Yamada, H., K. Hamamoto, A. Sugiura, and T. Tomana. 1988. Effects of controlled fruit temperature on maturation of apple fruits. J. Jpn. Soc. Hortic. Sci. 57:173-177.

Zhishen, J., T. Mengcheng, and W. Jianming. 1999. The determination of flavonoid contents in mulberry and their scavenging effects on superoxide radicals. Food Chem. 64:555-559. 